\title{
Thermal properties of polyethylene flame retarded with expandable graphite and intumescent fire retardant additives
}

\author{
Hermanus Joachim Kruger ${ }^{1}$, Walter Wilhelm Focke ${ }^{1, *}$, Washington Mhike ${ }^{1}$, Albertus Taute $^{1}$ and \\ Albert Roberson ${ }^{1}$ \\ ${ }^{1}$ SARChI Chair in Carbon Technology and Materials, Institute of Applied Materials, Department of \\ Chemical Engineering, University of Pretoria, Private Bag X20, Hatfield 0028, South Africa \\ Correspondence to: Walter W Focke (E-mail: walter.focke@up.ac.za)
}

\begin{abstract}
Low density polyethylene (LDPE) was flame retarded by combinations of expandable graphite (EG) with either ethylenediamine phosphate (EDAP) or 3,5-diamino benzoic acid phosphate (DABAP). Cone calorimeter, laser pyrolysis and open flame exposure tests (supported by video and infrared camera data capture and analysis) were conducted to assess ignition and burn behavior. Cone calorimeter results indicated substantial reductions in the peak heat release rates for all flame retarded samples but with reduced ignition times and increased flame out times. Smoke generation was suppressed in the presence of expandable graphite. Infrared and video data from open flame fire tests indicated cohesive bonding of expanded EG strings and thermal shielding properties in all binary systems. All binary systems delivered fire retardation exceeding any of the single fire retardant compounds. They were also able to withstand higher temperatures before ignition, burn through or sag occurred. All EDAP containing binary systems prevented sample burn through, maintaining structural integrity of samples until eventual melting of the polymer media occurred. TGA-Laser pyrolysis results confirmed the good thermal shielding imparted by the intumescent additives.
\end{abstract}

KEYWORDS Expandable graphite; exfoliation; intumescent flame retardant; thermal analysis; cone calorimeter

\section{INTRODUCTION}

Polyethylene has a high heat of combustion and practically no propensity for char formation.[1] As a result, polyethylene-based products present a potential fire hazard in deep-level underground mining applications. It is therefore necessary to flame retard polyethylene products with suitable additives for critical applications. A wide range of effective flame retardants are available [1,2]. Recent studies have highlighted the utility of expandable graphite (EG), intumescent flame retardants and their synergistic combinations in improving the fire behavior of polyethylene. [1, 3-8] Intumescent additives swell when exposed to fire or heat. They form a carbonaceous foam residue on the surface 
that acts as a heat insulator and a physical barrier to the transport of oxygen and pyrolysis products. [2, 9-11]

Expandable graphite (EG) is a partially oxidized, intercalated form of graphite. It contains intercalated guest species (e.g. sulfuric acid anions) in between the stacked graphene layers.[12, 13] A key property of expandable graphite is its tendency to exfoliate explosively, i.e. to expand rapidly in a worm-like manner when heated to high temperatures.[14-16] When this occurs at the surface of a polymer that faces upwards, a loose cover of fluffy vermicular graphite is deposited. This provides a protective barrier similar to that generated by conventional intumescent additives. Unlike the foam coating generated by conventional intumescent flame retardants however, this cover is weakly bonded to the polymer surface and there is no cohesion between adjacent EG "worms". Loss of this cover when the fire is associated with strong convection currents, or when a sample is exposed to a flame from below, leads to reduced performance.

Cone calorimetry is a modern method for measuring the ignition time, heat release rate, gaseous combustion products and other flammability characteristics of polymer samples. This fire testing method determines the transient heat release rate by measuring transient oxygen consumption rate in the exhaust gases. According to Babrauskas [17] heat release rate is the most important single variable in characterizing the flammability of products and thus the fire hazard they may pose. Cone calorimeter tests have highlighted historically that polyethylene features one of the highest heat release capacities and one of the highest heat release rates among the more widely used industrial polymers [2].

According to Han and Zhao [8] and Xie and Qu [4] better fire properties are possible with combinations of EG and other intumescent flame retardants. In spite of this, only a few such combinations have been explored to date. Therefore this contribution considered combinations of expandable graphite with two intumescent additives as flame retardants for polyethylene. The fire performance of these additives, on their own and in selected combinations, was studied using cone calorimeter fire testing, open flame tests and laser pyrolysis. A key objective of this study was to investigate whether addition of intumescent flame retardants to expandable graphite flame retarded systems improves the level of bonding achieved between exfoliated expandable graphite and the polymer surface within which it is contained. Furthermore there was a desire to achieve cohesion between the usually independent expanded graphite strings, thereby improving the overall barrier properties.

\section{EXPERIMENTAL}

\subsection{Materials}

Sasol Polymers supplied the low density polyethylene in powder form $(90 \%<850 \mu \mathrm{m})$. It was injection molding grade LT019/08 with density $0.919 \mathrm{~g} \mathrm{~cm}^{-3}$ and MFI $20.5 \mathrm{~g} / 10 \mathrm{~min} @ 190^{\circ} \mathrm{C} / 2.16 \mathrm{~kg}$. Carbon black grade N660 was sourced from Ferro Industrial Products. The expandable graphite grade ES250 B5 was sourced from Qingdao Kropfmuehl, China. The $\mathrm{d}_{10}, \mathrm{~d}_{50}$, and $\mathrm{d}_{90}$ particle sizes of this low expansion onset temperature grade were $313 \mu \mathrm{m}, 533 \mu \mathrm{m}$ and $807 \mu \mathrm{m}$ respectively (Mastersizer 2000, Malvern Instruments, Malvern, UK) and the density was $2.23 \pm 0.01 \mathrm{~g} \mathrm{~cm}^{-3}$. The phosphate salts of ethylenediamine and of 3,5-diaminobenzoic acid (DABAP) were synthesized using the procedures previously described. $[18,19]$ The structural formulas for these two compounds are presented in Scheme I. 


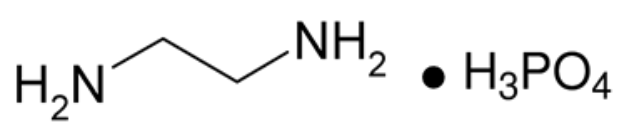

Ethylenediamine phosphate<smiles>Nc1cc(N)cc(C(=O)O)c1</smiles>

3,5-Diaminobenzoic acid phosphate

Scheme I. Structure of the two intumescent additives

\subsection{Preparation of the polyethylene compounds}

The expandable graphite and intumescent flame retardant additives were air dried before weighing out. They were dry-blended with the polyethylene powder by vigorous shaking in a large air-filled plastic bag. The mixtures were compounded on a $28 \mathrm{~mm}$ co-rotating intermeshing twin screw laboratory extruder $(\mathrm{L} / \mathrm{D}=16)$ at a screw speed of $140-220 \mathrm{rpm}$. The extruder screw design comprised intermeshing kneader elements with a forward transport action. The four extrusion processing stage temperatures, feed to die, were set at $120^{\circ} \mathrm{C}, 175^{\circ} \mathrm{C}, 175^{\circ} \mathrm{C}$ and $180{ }^{\circ} \mathrm{C}$ respectively. The extruded strands were granulated and the pellets were air-dried. A polyethylene compound containing $5 \mathrm{wt} . \%$ carbon black (N660) was prepared in a similar way. This compound was used as the reference sample for all fire testing. The compounds containing $27 \mathrm{wt} \%$ intumescent additive (EDAP or DABAP) also contained $5 \mathrm{wt} . \%$ carbon black. This maintained a consistent range of dark product sheets consistent with those delivered for expandable graphite containing compounds. This was done to ensure comparable absorption of infrared radiation during cone calorimeter testing and laser pyrolysis experiments.

Test specimens for cone calorimeter testing were prepared by pressing the pellets into flat sheets in a hot press set at $180{ }^{\circ} \mathrm{C}$. These sheets were prepared at sheet dimensions of $100 \mathrm{~mm} \times 100$ $\mathrm{mm} \times 3.2 \pm 0.1 \mathrm{~mm}$. An ASTM D5420 drop impact testing disc was selected for open flame fire testing. The circular discs (diameter $68.5 \mathrm{~mm}, 2.93 \pm 0.02 \mathrm{~mm}$ thick) were injection molded directly on an Engel EC088 machine.

\subsection{Characterization and analysis}

Scanning electron microscopy. SEM images were obtained using an ultrahigh resolution field emission SEM (HR FEGSEM Zeiss Ultra Plus 55) with an InLens detector at acceleration voltages of as low as $1 \mathrm{kV}$ to ensure maximum resolution of surface detail. No electro-conductive coating was applied on the graphite particles.

SEM micrographs of the temperature driven dynamic expandable graphite exfoliation processes were also obtained using a scanning electron microscope (FEI QUANTA 200 ESEM) fitted with a heating stage. The graphite flakes were placed inside a crucible and mounted in the heating stage. They were viewed at $200 \times$ magnification. The pressure was $0.5 \mathrm{kPa}$, voltage $20 \mathrm{kV}$, spot size 67 and a working distance of $16-20 \mathrm{~mm}$. Temperature was ramped at $20{ }^{\circ} \mathrm{C} \mathrm{min}^{-1}$.

Thermal analysis. Thermogravimetric analysis (TGA) was performed using the dynamic temperature scan method. Two different instruments, a TA Instruments SDT Q600 and a Mettler Toledo TGA $850 \mathrm{e}$ instrument were employed. Typically about $10-15 \mathrm{mg}$ of sample was placed in an open $50 \mu \mathrm{L}$ alumina pan. Sample size was reduced to below $5 \mathrm{mg}$ for intumescent materials such as expandable graphite which were placed in $150 \mu \mathrm{m}$ alumina sample holders and covered with lids (pin hole) to 
ensure containment of solids. Temperature was scanned from below $50{ }^{\circ} \mathrm{C}$ to $900{ }^{\circ} \mathrm{C}$ at a scan rate of $10{ }^{\circ} \mathrm{C} \mathrm{min}{ }^{-1}$ with gas (nitrogen or air) flowing at a rate of $50 \mathrm{~mL} \mathrm{~min}{ }^{-1}$.

Thermal expansion measurements were conducted on a TA instruments Q400 Thermo Mechanical Analyzer (TMA). Sufficient expandable graphite powder was placed in an alumina sample pan such that the bed height was between $35 \mu \mathrm{m}$ and $40 \mu \mathrm{m}$. The flake expansion behavior was measured with a flat-tipped standard expansion probe using an applied force of $0.005 \mathrm{~N}$. The temperature was scanned from $30{ }^{\circ} \mathrm{C}$ to $600{ }^{\circ} \mathrm{C}$ at a scan rate of $10{ }^{\circ} \mathrm{C} \mathrm{min}^{-1}$ in a nitrogen atmosphere. The expansion relative to the original powder bed height was reported.

Open flame fire testing. Open flame fire tests were conducted on the injection-molded circular discs in two different configurations. In the first configuration (Figure 1A) the test specimens were mounted vertically and exposed to a $4 \mathrm{~cm}$ butane flame perpendicular to the sample surface. Infrared footage was recorded at a $45^{\circ}$ angle to the sample surface at a distance of $20 \mathrm{~cm}$ from behind each sample. In the second configuration (Figure 1B) the sample discs were mounted horizontally and exposed to a $4 \mathrm{~cm}$ butane flame placed at $45^{\circ}$ to the sample surface. Infrared footage was recorded perpendicular to the sample surface at a distance of $20 \mathrm{~cm}$ from above the sample.



Fig. 1 Diagrammatic representation of (A) Vertical (top-down view) and (B) Horizontal (side view) configurations used for open flame fire testing.

Laser pyrolysis. Samples with a mass of ca. $40 \mu \mathrm{m}$, cut from injection molded discs, were placed in $6.3 \mathrm{~mm}$ diameter alumina pans for laser pyrolysis studies. Mass loss was recorded with a Perkin-Elmer TGA 4000 thermogravimetric analyzer under quiescent conditions, i.e. the gas flow was shut down. First the samples were heated to $200{ }^{\circ} \mathrm{C}$ and kept at this temperature for ca. $20 \mathrm{~min}$ in order to melt the compounds and completely fill the area of the pans. This allowed removal of nonhomogeneity in the polymeric media and allowed the samples to settle into a flat surface. These samples were allowed to cool for 10 minutes which proved sufficient for the small sample size used. These samples were then heated to $100{ }^{\circ} \mathrm{C}$ at $10{ }^{\circ} \mathrm{C} \mathrm{min}^{-1}$ and then exposed to laser energy generated by a Class- $4 \mathrm{CO}_{2}$ laser. The beam power was set at $2 \mathrm{~W}$. This exposure and temperature was 
maintained for at least $30 \mathrm{~min}$. Three specimens of each composition were tested and average values are reported.

Cone calorimeter flammability testing. The ISO 5660-1 standard was followed in performing the cone calorimeter tests using a Dual Cone Calorimeter (Fire Testing Technology (UK) Ltd.). Three specimens of each composition were tested and average values are reported. The sheet dimensions were $100 \mathrm{~mm} \times 100 \mathrm{~mm} \times 3.2 \mathrm{~mm}$. They were placed horizontally on aluminum foil and exposed perpendicularly from above to an external heat flux of $35 \mathrm{~kW} \mathrm{~m}^{-2}$.

\section{RESULTS AND DISCUSSION}

\subsection{Characterization}

A comprehensive characterization of the commercial expandable graphite (EG) was previously reported.[20] This flame retardant additive was fabricated by treating natural graphite flakes with an oxidant in the presence of sulfuric acid. The expansion onset temperature, as determined by thermomechanical analysis, was ca. $225^{\circ} \mathrm{C}$. The EG released a mixture of carbon dioxide, carbon monoxide and sulfur dioxide during the exfoliation process.[20]

The SEM micrograph in Figure 2A shows the morphology of the EDAP powder particles. The flake-like morphology of the DABAP crystals is shown in Figure 2B. The expandable graphite particles also had a flake-like nature but the flakes were much larger. Figure 3 shows a micrograph of the vermicular residues of the expanded graphite sample taken in the ESEM and a close-up micrograph obtained in the FEGSEM. The expansion of the low temperature EG resulted in "worms" with a fairly regular cross-section. According to the manufacturer, the volume expansion of the EG was at least $250 \mathrm{~mL} \mathrm{~g}^{-1}$.

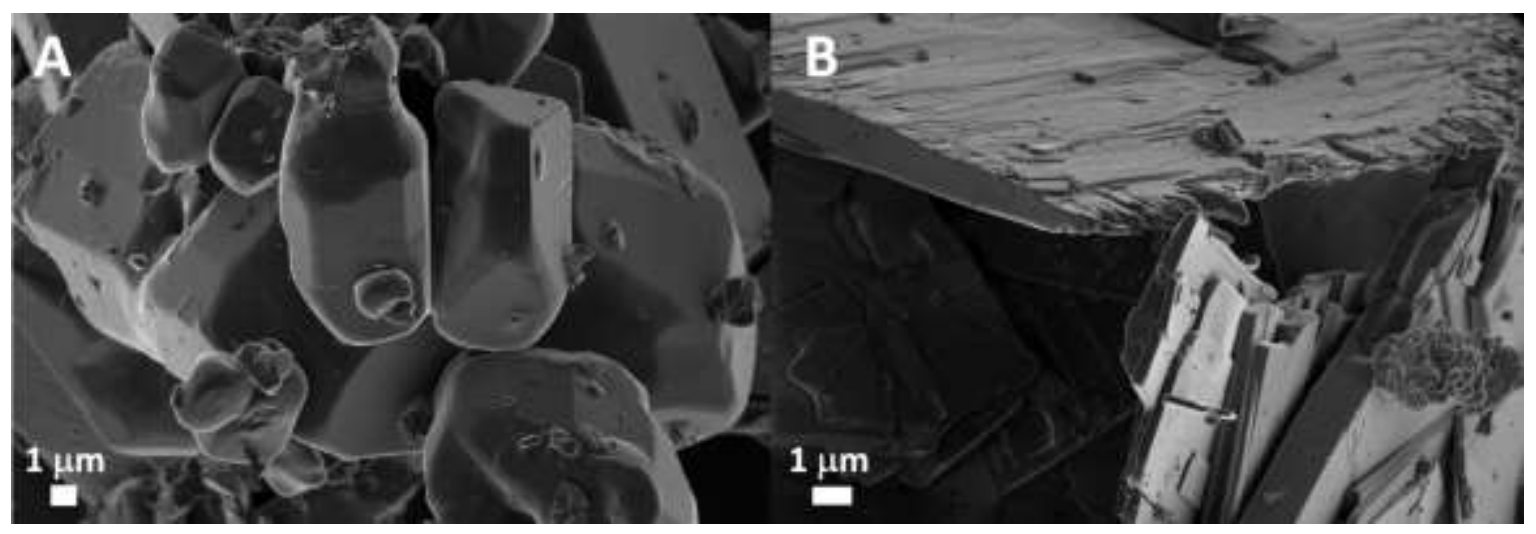

Fig. 2 FEGSEM micrographs of the (A) ethylenediamine phosphate (EDAP) powder and (B) the diaminobenzoic acid phosphate crystals (DABAP). 


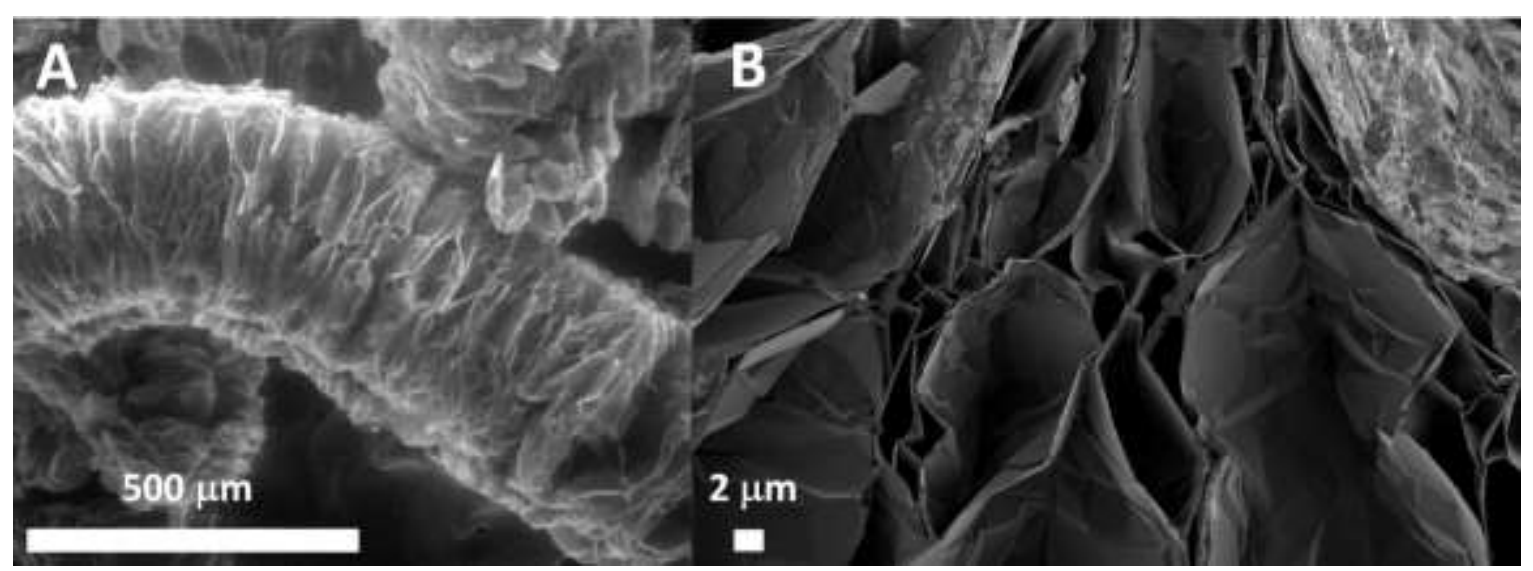

Fig. 3 Micrographs of the expandable graphite after exfoliation in (A) the ESEM and (B) the FEGSEM.

\subsection{Thermal analysis of the flame retardant additives}

The key property of expandable graphite in fire retardant applications is the ability to exfoliate within a narrow temperature range. Figure 4 shows the TMA expansion trace obtained in $\mathrm{N}_{2}$ and the TGA mass loss curve obtained in air for the expandable graphite. The EG showed four mass loss steps when heated in air. There was a minor mass loss below $150{ }^{\circ} \mathrm{C}$ indicating moisture loss of ca. $0.5 \%$. This was succeeded by a second mass loss which initiated at $210{ }^{\circ} \mathrm{C}$ and reached a peak mass loss rate at $226^{\circ} \mathrm{C}$. This event was associated with an additional mass loss of $4.5 \%$ (total mass loss of $5 \%$ ). The TMA traces indicated that this second mass loss event is associated with expansion of the EG. The third mass loss event commenced at $361{ }^{\circ} \mathrm{C}$, peaked at $408{ }^{\circ} \mathrm{C}$ and contributed a further mass loss of $11 \%$ (total mass loss of approximately $16 \%$ ) by $600{ }^{\circ} \mathrm{C}$. The TMA trace indicates that this mass loss was connected to a second gas release that ultimately lead to full exfoliation of the graphite. The apparent contractions in the TMA curves are attributed to the loss of gas pressure after the exfoliation events, i.e. the applied pressure from the TMA probe was able to compress the "fluffy" exfoliated graphite layer that was formed. The final mass loss event started at $705{ }^{\circ} \mathrm{C}$ and peaked at $798{ }^{\circ} \mathrm{C}$, corresponding to the oxidation of the graphite residue. The residual mass at $900{ }^{\circ} \mathrm{C}$ was $4.2 \%$. Both the TMA and TGA curves in Figure 4 show that the EG underwent a two-stage exfoliation. The reason for this is not known at this stage. Differential scanning calorimetry (DSC) results (presented in [19] but not shown here) indicated that both exfoliation events are endothermic in nature.

Figure 5 shows TGA and derivative thermogravimetric (DTG) curves for the two intumescent flame retardants recorded in an air atmosphere. The DTG curve indicates that mass loss for the DAPAB occurred in four steps. The minor mass loss $(1 \%)$ below $200{ }^{\circ} \mathrm{C}$ probably reflects the loss of moisture. Starting at a temperature of about $225^{\circ} \mathrm{C}$, an event associated with a steep mass loss (ca. $16 \%$ ) occurred. This probably reflects the loss of $\mathrm{CO}_{2}$ due to the decarboxylation of the DABAP. The theoretical mass loss for decarboxylation is $17.6 \%$. Mass loss continued and reached another peak value at a temperature of $465{ }^{\circ} \mathrm{C}$. The DSC curves (not shown here but presented in [19]) indicated that this reaction is exothermic while all other mass loss steps are endothermic in nature. However, in a nitrogen atmosphere this step was also endothermic. This is attributed to a char-forming decomposition reaction that also released ammonia gas. The pyrolysis of the char continued as the temperature was raised. It reached a maximum rate at ca. $622{ }^{\circ} \mathrm{C}$ and was complete by about $750{ }^{\circ} \mathrm{C}$. The carbonized char residue that remained represented just above $2 \%$ of the initial DABAP mass. 


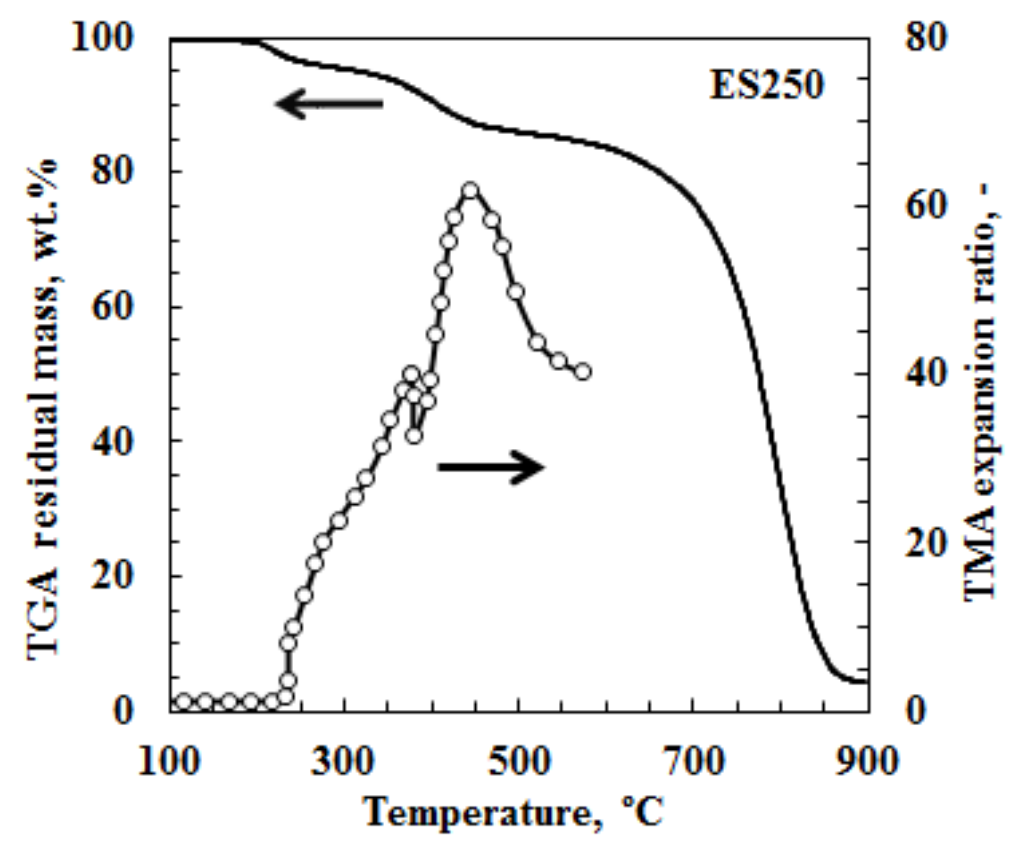

Fig. 4 TGA (in air) and TMA (in nitrogen) curves for the low exfoliation onset temperature expandable graphite. In the TMA and TGA experiments the temperature was scanned to $600{ }^{\circ} \mathrm{C}$ and $900{ }^{\circ} \mathrm{C}$ respectively at a scan rate of $10{ }^{\circ} \mathrm{C} \mathrm{min}{ }^{-1}$ with gas flowing at a rate of $50 \mathrm{~mL} \mathrm{~min}^{-1}$. In the TMA experiment, a flat-tipped standard expansion probe was used with an applied force of $0.005 \mathrm{~N}$.


Fig. 5 TGA (thick line) and DTG (thin blue line) curves for (A) ethylenediamine phosphate (EDAP) and (B) 3,5diaminobenzoic acid phosphate. Temperature was scanned to $900{ }^{\circ} \mathrm{C}$ at a scan rate of $10{ }^{\circ} \mathrm{C} \mathrm{min}{ }^{-1}$ with air flowing at a rate of $50 \mathrm{~mL} \mathrm{~min}{ }^{-1}$.

A DSC scan indicated a sharp endothermic peak with an onset temperature of $257^{\circ} \mathrm{C}$ reminiscent of a melting event.[19] Additionally TMA indicated softening of the material at this temperature.[19] This means that the melting of DABAP commenced with simultaneously thermal decomposition.

The derivative thermogravimetric (DTG) curve (Figure $5 \mathrm{~A}$ ) indicates that the decomposition of the EDAP was significantly more complicated. The melting and decomposition of this additive 
commences just above $200{ }^{\circ} \mathrm{C}$. Melting with subsequent decomposition was indicated by two sharp DTG peaks located at $225{ }^{\circ} \mathrm{C}$ and $245^{\circ} \mathrm{C}$ respectively. This is attributed to a reaction that also released ammonia vapor. Multiple peaks are observed between $280{ }^{\circ} \mathrm{C}$ and $480{ }^{\circ} \mathrm{C}$. Their number and positions vary with each scan. This suggests that the peaks are associated with the erratic release of gaseous products during the on-going char-forming decomposition reactions. The well-defined DTG peak located at ca. $615{ }^{\circ} \mathrm{C}$ is associated with the air oxidation reaction. The DSC curve (not shown) indicates that this reaction is exothermic whereas all the others are endothermic in nature. The carbonized char residue remaining at $900{ }^{\circ} \mathrm{C}$ was only about $6 \%$.

\subsection{Open flame tests}

Figure 6 shows the open flame test results for the carbon black pigmented polyethylene and the compound containing $10 \mathrm{wt} . \%$ each of EG and EDAP. Samples were mounted horizontally and the flame was applied from below as shown in Figure 1 B. The temperature profiles shown were measured along a line passing approximately through the center of the sheet where the flame impinged. They were recorded by the IR camera at selected time intervals and indicate the temperature variation from the left side to the right side. These curves were extracted from the recorded infrared footage. The temperature profiles are also shown for time instants just after initiation of sagging, ignition- or burn-through occurred.
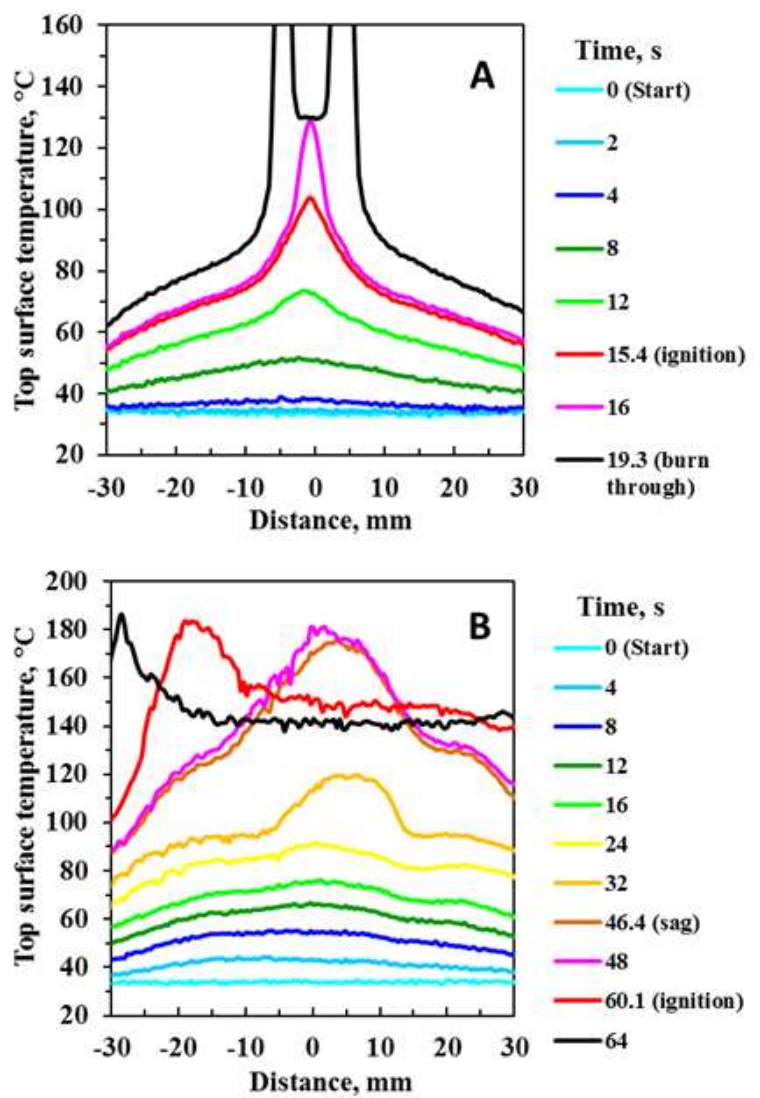

Fig. 6 Representative open flame test temperature profiles measured with an IR camera with the sample disc in a horizontal position. The $4 \mathrm{~cm}$ butane flame was applied from below at a $45^{\circ}$ angle. The IR camera was positioned above and recorded the top surface temperature as a function of time and position. The profiles displayed indicate the temperature variation from left to the right of the samples passing through the center where the flame impinged the sheet. A. Polyethylene with 5 wt.\% carbon black. B. Polyethylene with ES250/EDAP at 10/10 wt.\%. 
The profiles for the non-flame retarded sheet quickly developed a sharp temperature peak that resulted in ignition within a short period of time (15.4 s for this sample). A hole opened up in the sheet less than three seconds later. The strange shape of the temperature profile obtained at $19.3 \mathrm{~s}$ is an artifact of the hole that burned into the sheet. By comparison the temperature profiles for the flame retarded sample are flatter at similar times. The polymer is heated over a larger area owing to the shielding effect of the intumescent layer that forms. The temperature even reached values that exceeded the melting point of the material causing a softening that resulted in sagging. Only then did ignition occur. Table 1 summarizes the open flame test data.

Table 1 Open flame fire testing summary

\begin{tabular}{|c|c|c|c|c|c|c|}
\hline \multirow[b]{2}{*}{ Property } & \multirow[b]{2}{*}{ Units } & \multicolumn{5}{|c|}{ ES250/EDAP, wt.\% } \\
\hline & & $\mathbf{0 / 0}$ & $10 / 0$ & $0 / 27$ & $10 / 10$ & $10 / 20$ \\
\hline \multicolumn{7}{|l|}{ Vertical open flame } \\
\hline Time to ignition $\left(t_{\mathrm{ign}}\right)$ & $\mathrm{s}$ & $22 \pm 1$ & $18 \pm 11$ & $11 \pm 1$ & - & - \\
\hline Time to sag initiation & $\mathrm{s}$ & - & $27 \pm 1$ & $27 \pm 3$ & $25 \pm 0$ & $25 \pm 0$ \\
\hline Time to burn through & $\mathrm{s}$ & $20 \pm 1$ & $37 \pm 1$ & $34 \pm 0$ & n.a. & n.a. \\
\hline Polymer flow / Droplets & $\mathrm{Y} / \mathrm{N}$ & $\mathrm{Y}$ & $\mathrm{N}$ & $\mathrm{N}$ & $\mathrm{N}$ & $\mathrm{N}$ \\
\hline \multicolumn{7}{|l|}{ Horizontal open flame } \\
\hline Time to ignition $\left(t_{\mathrm{ign}}\right)$ & $\mathrm{s}$ & $16 \pm 2$ & $33 \pm 2$ & $29 \pm 4$ & $* 58 \pm 2$ & $* 51 \pm 4$ \\
\hline Time to sag initiation & $\mathrm{s}$ & - & - & $39 \pm 4$ & $48 \pm 2$ & $40 \pm 3$ \\
\hline Time to burn through & $\mathrm{s}$ & $20 \pm 0$ & $35 \pm 0$ & $39 \pm 3$ & n.a. & n.a. \\
\hline Polymer flow / Droplets & $\mathrm{Y} / \mathrm{N}$ & Y & $\mathrm{N}$ & $\mathrm{N}$ & $\mathrm{N}$ & $\mathrm{N}$ \\
\hline & & \multicolumn{5}{|c|}{ ES250/DABAP, wt.\% } \\
\hline Property & Units & $\mathbf{0 / 0}$ & $10 / 0$ & $0 / 27$ & $10 / 10$ & $10 / 20$ \\
\hline \multicolumn{7}{|l|}{ Vertical open flame } \\
\hline Time to ignition $\left(t_{\mathrm{ign}}\right)$ & $\mathrm{s}$ & $22 \pm 1$ & $18 \pm 11$ & $13 \pm 2$ & $12 \pm 0$ & $11 \pm 1$ \\
\hline Time to sag initiation & $\mathrm{s}$ & - & $27 \pm 1$ & $31 \pm 1$ & $24 \pm 0$ & $24 \pm 0$ \\
\hline Time to burn through & $\mathrm{s}$ & $20 \pm 1$ & $37 \pm 1$ & $34 \pm 0$ & $51 \pm 1$ & n.a. \\
\hline Polymer flow / Droplets & $\mathrm{Y} / \mathrm{N}$ & $\mathrm{Y}$ & $\mathrm{N}$ & $\mathrm{N}$ & $\mathrm{N}$ & $\mathrm{N}$ \\
\hline \multicolumn{7}{|l|}{ Horizontal open flame } \\
\hline Time to ignition $\left(t_{\mathrm{ign}}\right)$ & $\mathrm{s}$ & $16 \pm 2$ & $33 \pm 2$ & $19 \pm 1$ & $27 \pm 1$ & $30 \pm 3$ \\
\hline Time to sag initiation & $\mathrm{s}$ & - & - & $34 \pm 2$ & $33 \pm 10$ & $40 \pm 7$ \\
\hline Time to burn through & $\mathrm{s}$ & $20 \pm 0$ & $35 \pm 0$ & $29 \pm 1$ & $40 \pm 5$ & $45 \pm 0$ \\
\hline Polymer flow / Droplets & $\mathrm{Y} / \mathrm{N}$ & $\mathrm{Y}$ & $\mathrm{N}$ & $\mathrm{N}$ & $\mathrm{N}$ & $\mathrm{N}$ \\
\hline
\end{tabular}

Figures 7A and 7B show temperature profiles for the vertical test specimen after $16 \mathrm{~s}$ of open flame exposure from behind. The profiles displayed indicate the measured temperature variation from the bottom to the top of the sample. One may note that the single flame retardant systems and the nonflame retarded sample each deliver a sharper temperature curve around the point of flame exposure. All the binary flame retarded systems lowered the local increase at the point of flame exposure due to continuous intumescence and formation of an effective thermal barrier at this point. This spread the heat towards the perimeter of the test specimen, lowering the chance of burn through at similar exposure times. 

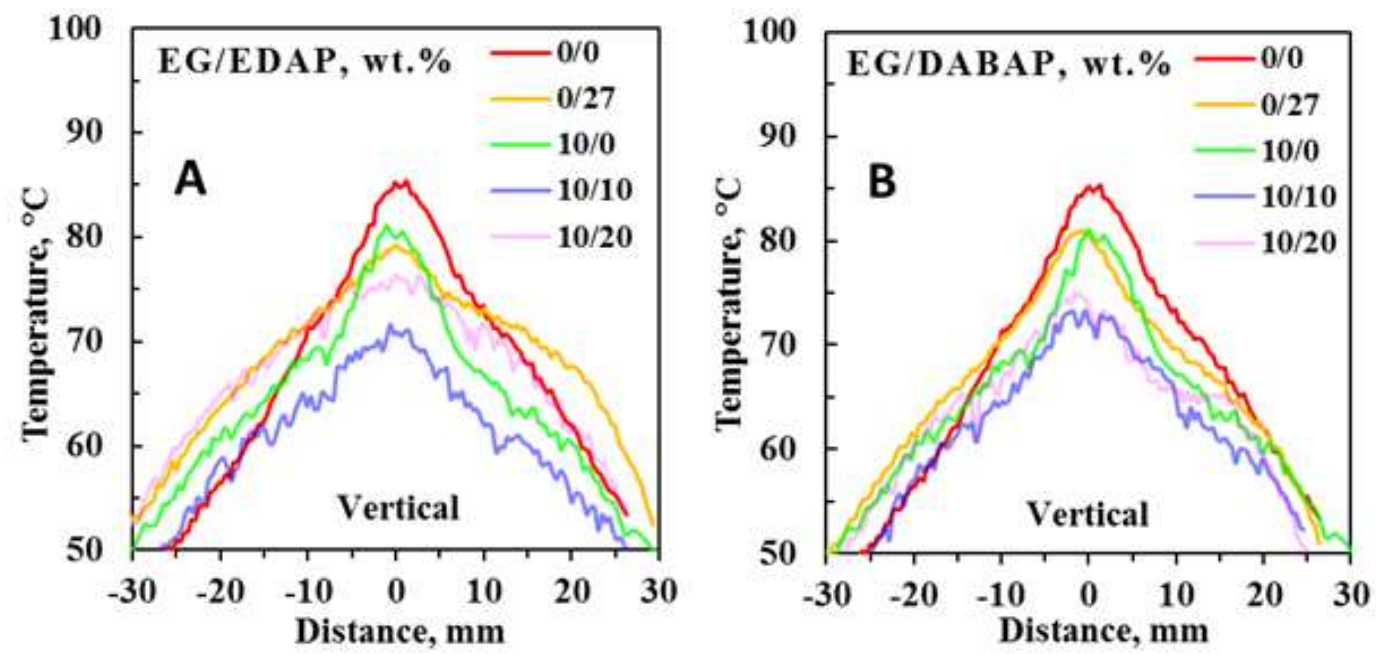

Fig. 7 Open flame test temperature profiles from top to bottom right on vertical discs after $16 \mathrm{~s}$ of exposure to the $4 \mathrm{~cm}$ butane flame. Vertically mounted specimens were exposed with the flame perpendicular to the sample surface. Infrared footage was recorded on the rear of each sample surface at a 45 degree angle at a distance of $20 \mathrm{~cm}$ from each sample.

Figure $8 \mathrm{~A}$ and $8 \mathrm{~B}$ show linear temperature profiles at the top surface for horizontal test specimens exposed to flame from below for 16 seconds. The profiles displayed indicate the temperature variation from the left to right. These results indicate an even sharper peak for the nonflame retarded sample. The 27 wt.\% DABAP samples showed a further increase in surface temperature towards the top point of the exposed samples. This was caused by increased radiant heat absorption in the DABAP sample of the heat which rose across the sample surface from the point of flame exposure. Addition of EG prevented this heat absorption due to the improved thermal barrier delivered by the binary samples. A more peaked temperature curve was measured for the horizontal samples while the vertical samples maintained a bell curve shape. This phenomenon may be attributed to the formation of thicker thermal barrier around the point of exposure. This barrier lowered the spread of heat to the immediate surrounding area, causing temperature increases above the point of exposure in the non-foamed region of the sample alone.
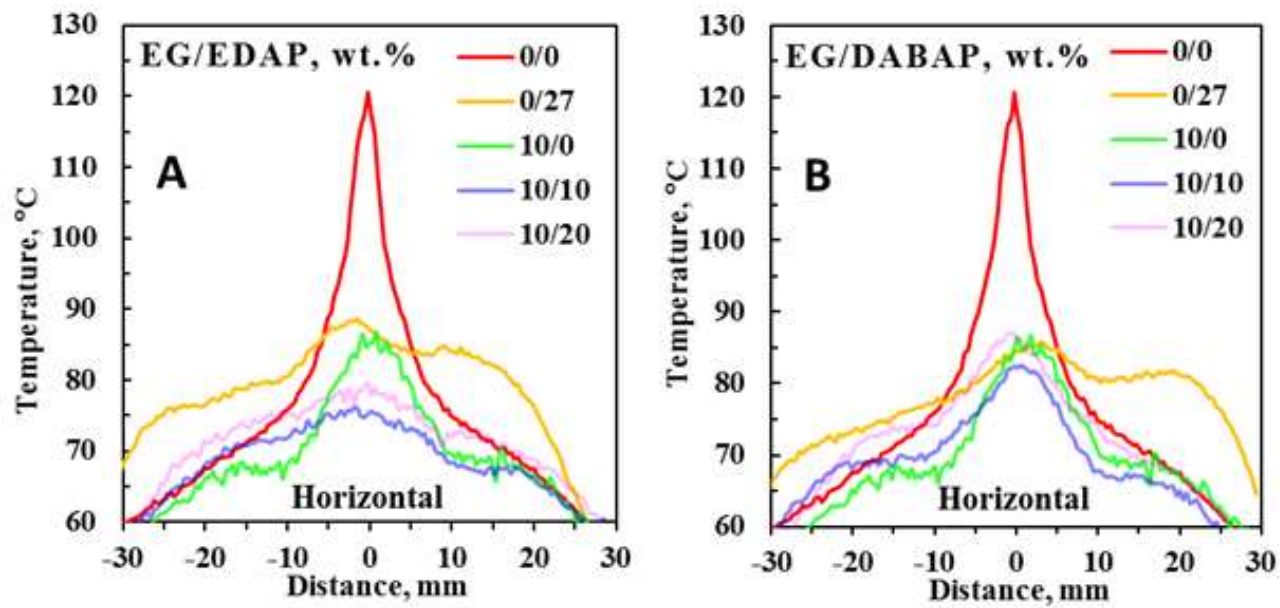

Fig. 8 Open flame test temperature profiles from left to right on horizontal discs after 16 seconds of exposure to a $4 \mathrm{~cm}$ butane flame. The horizontally mounted test specimens were exposed to the flame held at 45 degrees from below while infrared footage was recorded perpendicular to the top sample surface at a distance of $20 \mathrm{~cm}$ from the sample.

Increased temperature maxima were measured across the first 8 seconds of exposure to the flame in the $10 \mathrm{wt} . \% \mathrm{EG}$ and $27 \mathrm{wt} . \%$ DABAP samples. The rate of temperature increase in these 
samples then slowed as intumescence commenced and the barrier performance reached a thermally thick level of performance. The binary systems were able to reach this level of performance earlier reducing the maximum temperature reached as heat was conducted away from the point of flame exposure across the thermal barrier. The temperature in the non-flame retarded sample increased at a much higher rate at the point of exposure due to the continuous reduction in sample thickness caused by polymer flow and droplet formation.

Figure 9 shows and Table 1 lists the ignition and flame out times during open flame fire testing for the various samples. During vertical and horizontal fire testing all fire retarded samples prevented dripping and even polymer flow across the sample. EDAP combinations delivered very effective burn through prevention abilities. All binary EDAP containing samples blocked burnthrough when exposed to flame in a vertical or horizontal configuration. Although slightly less effective at fire retardation than EDAP when used alone, DABAP delivered burn through prevention at $20 \mathrm{wt} . \%$ loading with EG and good fire retardant properties throughout all tests. Addition of the flame retardants increased the propensity of the material to ignite with the exclusion of the binary systems containing EG and EDAP. EDAP and EG showed exceptional synergism in open flame fire testing preventing ignition in all fire retarded samples tested. These compounds only ignited when the edge of the material was exposed to the test flame when the sample, after extended exposure, reached the melting temperature of the polymer and sagged, exposing the top edge of the samples. Very good bonding of loose EG strings was observed with both EDAP and DABAP present. The EDAP binary systems showed the best cohesive thermal barrier formation thus yielding excellent fire retardation as a result.[21] All flame retarded samples prevented polymer flow.
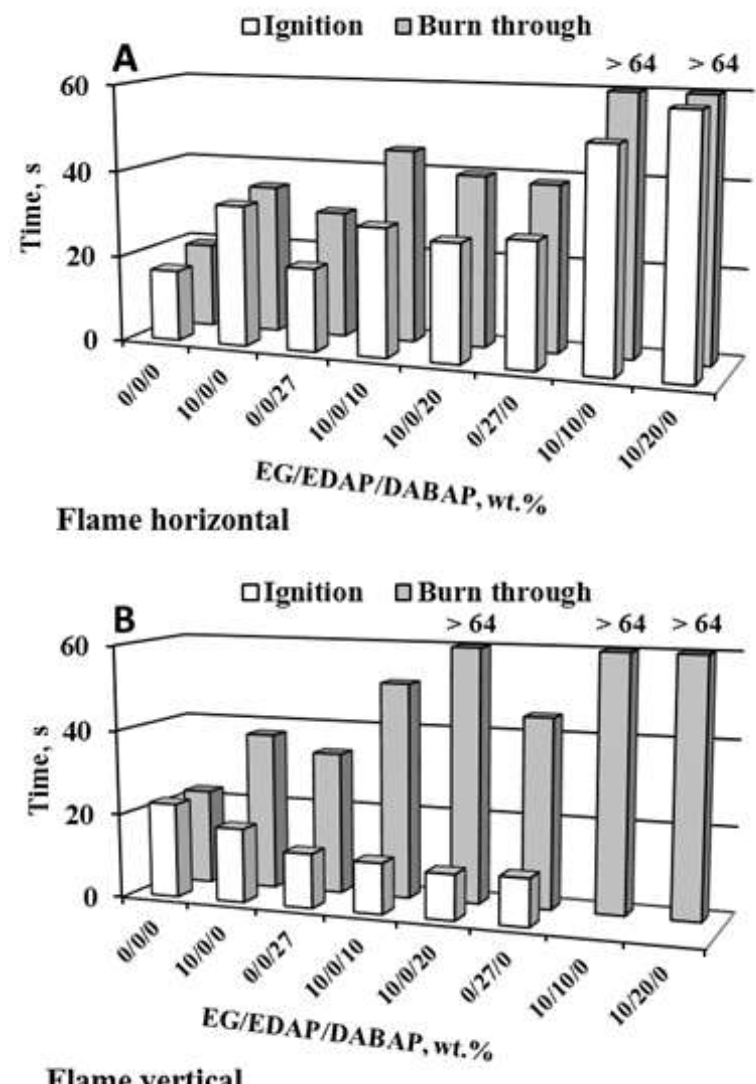

Fig. 9 Ignition and burn through times for (A) horizontal and (B) vertical flame tests. Sample discs were either mounted horizontally and exposed to a $4 \mathrm{~cm}$ butane flame at 45 degrees from below or vertically and exposed to the same flame perpendicular to the surface. 


\subsection{Laser Pyrolysis}

The laser pyrolysis experiment simulated the cone calorimeter test at a micro scale. An Edinburgh PL6 $\mathrm{CO}_{2}$ Laser operating at $10.6 \mu \mathrm{m}$ was used. The laser power was set at $2 \mathrm{~W}$ and the beam size adjusted to fit the internal diameter of the TGA pans $(7.14 \mathrm{~mm})$ so that it simulated a radiant heat flux of $50 \mathrm{~kW} \mathrm{~m}{ }^{-2}$. The laser power was switched on a time $\mathrm{t}=0$ and the mass loss followed as a function of time while the temperature was simultaneously measured below the sample pan. Figure 10 summarizes the temporal evolution of the temperature measured at the bottom of samples exposed to laser irradiation. Figure 11 shows the corresponding mass loss recorded in the TGA. Note that the temperature rapidly rose to a quasi-steady state value within a few minutes whereas mass loss continued for tens of minutes. This means that the temperature curves provide an indication of the thermal shielding offered by the flame retardant additives. When comparing the temperature and residual mass loss curves for the different samples one may note a direct connection between the steady-state temperature reached and the residual mass. This trend indicates that samples with improved mass loss resistance were those where the surface barrier layer prevented said samples from reaching higher temperatures, i.e. the fire barrier limited heat transfer to the polymeric material below where the temperature probe was located. Compared to the carbon black filled reference, all flame retarded samples showed improved performance reaching lower steady state temperatures and showing reduced mass loss. The sample containing only expandable graphite did not do as well as those containing an intumescent additive only. Furthermore, there was very good synergism between DABAP and EG. All DABAP binary systems outperformed the $27 \mathrm{wt} . \%$ DABAP and the $10 \mathrm{wt} . \%$ EG systems by a very large margin. However, the $27 \mathrm{wt} . \%$ EDAP system outperformed the $27 \mathrm{wt} . \%$ DABAP system in all respects. Interestingly, the best results are achieved by the 10/10 wt. $\%$ EG/DABAP system although EDAP binary systems outperformed DABAP systems in other fire tests.
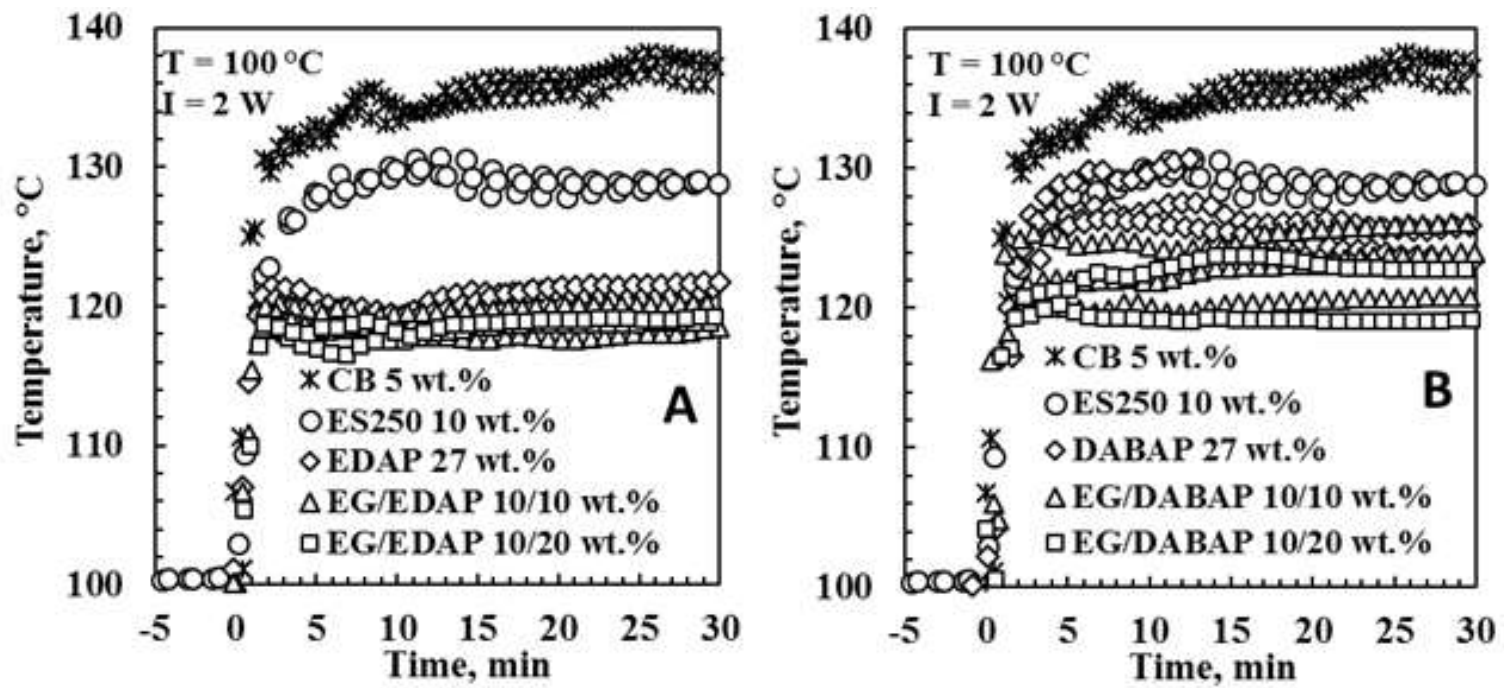

Fig. 10 TGA-laser pyrolysis sample temperature as a function of time. The laser power was set at $2 \mathrm{~W}$ and the initial sample temperature was $100{ }^{\circ} \mathrm{C}$. A. Combinations of expandable graphite (EG) with (A) ethylenediamine phosphate and (B) 3,5diaminobenzoic acid phosphate. 



Fig. 11 TGA-laser pyrolysis mass loss as a function of time. The laser power was set at $2 \mathrm{~W}$ and the initial sample temperature was $100^{\circ} \mathrm{C}$. A. Combinations of expandable graphite (EG) with (A) ethylenediamine phosphate and (B) 3,5diaminobenzoic acid phosphate were used.

\subsection{Cone calorimeter fire testing}

A detailed analysis of the cone calorimeter results was previously reported by Kruger et al. [18] Table 2 and Figure 12 summarize information pertinent to the present discussion. Figure 12 confirms that the addition of the EG reduced the mass loss rate (MLR). This can be attributed to the expansion of the intercalated graphite which forms a low density layer of loose, 'worm like' structures at the surface. Visual inspection showed that DABAP containing compounds formed a denser charred foam layer at the polymer interface.

Table 2. Cone calorimeter data summary for time to ignition $\left(t_{\mathrm{ign}}\right)$, time to flame out $\left(t_{\mathrm{fo}}\right)$, time to peak heat release rate $(t-$ $p H R R)$, peak heat release rate $(p H R R)$, fire performance index $(F P I)$ and residual mass.

\begin{tabular}{|c|c|c|c|}
\hline Sample & $\begin{array}{c}t_{\text {ign }} \\
\text { S }\end{array}$ & $\begin{array}{l}t_{\mathrm{fo}} \\
\mathrm{s}\end{array}$ & $\begin{array}{c}t-p H R R \\
\mathrm{~s}\end{array}$ \\
\hline Polyethylene (5 wt.\% CB) & $58.3 \pm 2.5$ & $773 \pm 307$ & $177 \pm 6$ \\
\hline ES250 (10 wt.\%) & $45.7 \pm 1.5$ & $1049 \pm 12$ & $97 \pm 3$ \\
\hline EDAP (27 wt.\%) & $41.3 \pm 0.6$ & $878 \pm 190$ & $73 \pm 3$ \\
\hline DABAP (27 wt.\%) & $33.0 \pm 5.2$ & $537 \pm 69$ & $105 \pm 13$ \\
\hline ES250/EDAP (10/10 wt.\%) & $45.3 \pm 1.2$ & $1046 \pm 17$ & $97 \pm 8$ \\
\hline ES250/DABAP (10/10 wt.\%) & $37.7 \pm 0.6$ & $1172 \pm 48$ & $80 \pm 0$ \\
\hline ES250/EDAP (10/20 wt.\%) & $46.7 \pm 2.5$ & $948 \pm 20$ & $128 \pm 53$ \\
\hline ES250/DABAP (10/20 wt.\%) & $37.7 \pm 1.5$ & $1138 \pm 24$ & $78 \pm 3$ \\
\hline Sample & $\begin{array}{c}\text { pHRR } \\
\mathrm{kW} \mathrm{m}^{-2}\end{array}$ & $\begin{array}{c}F P I^{*} \\
\mathrm{~s} \mathrm{~m}^{2} \mathrm{~kW}^{-1}\end{array}$ & $\begin{array}{c}\text { Residue } \\
\text { wt. } \%\end{array}$ \\
\hline Polyethylene (5 wt.\% CB) & $710 \pm 109$ & $0.084 \pm 0.014$ & $8.3 \pm 3.2$ \\
\hline ES250 (10 wt.\%) & $231 \pm 7$ & $0.197 \pm 0.007$ & $18.5 \pm 0.3$ \\
\hline EDAP (27 wt.\%) & $230 \pm 5$ & $0.180 \pm 0.004$ & $26.1 \pm 2.7$ \\
\hline DABAP (27 wt.\%) & $400 \pm 16$ & $0.083 \pm 0.016$ & $22.4 \pm 0.5$ \\
\hline ES250/EDAP (10/10 wt.\%) & $197 \pm 10$ & $0.231 \pm 0.017$ & $26.3 \pm 0.4$ \\
\hline ES250/DABAP (10/10 wt.\%) & $209 \pm 8$ & $0.180 \pm 0.009$ & $27.8 \pm 0.4$ \\
\hline ES250/EDAP (10/20 wt.\%) & $187 \pm 1$ & $0.250 \pm 0.014$ & $29.5 \pm 1.0$ \\
\hline ES250/DABAP (10/20 wt.\%) & $231 \pm 11$ & $0.163 \pm 0.012$ & $30.6 \pm 1.3$ \\
\hline
\end{tabular}

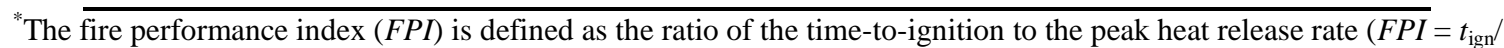
pHRR). 

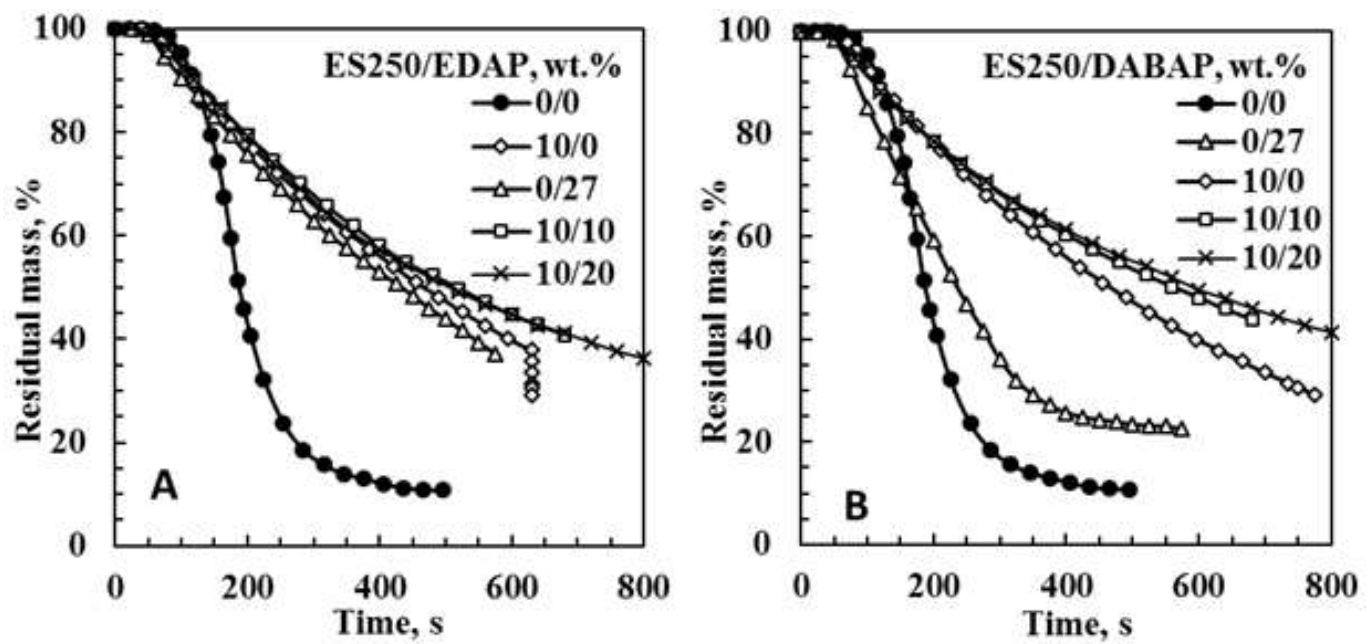

Fig. 12 Cone calorimeter mass loss curves for the polyethylene compounds with expandable graphite and EDAP or DABAP. The sample sheets were backed by aluminum foil and their dimensions were $100 \mathrm{~mm} \times 100 \mathrm{~mm} \times 3.2 \mathrm{~mm}$. They were exposed horizontally to an external heat flux of $35 \mathrm{~kW} \mathrm{~m}^{-2}$.

In cone calorimeter testing (Table 2 ) the time to ignition $\left(t_{\text {ign }}\right)$ was $58 \pm 3 \mathrm{~s}$ for the neat polyethylene and $46 \pm 1 \mathrm{~s}$ for the compound containing $10 \mathrm{wt} . \%$ ES250 but it decreased to $33 \pm 5$ for the compound containing $27 \mathrm{wt} . \%$ DABAP. These values mirror the pattern observed in open flame fire testing. See Table 2 for other values. Table 2 reveals that the time to flame out showed considerable variability. It was $773 \pm 307$ for the neat polyethylene and $539 \pm 69$ for the $27 \mathrm{wt} . \%$ DABAP compound but was longer than both these times for all other compounds.

The fire performance index $(F P I)$ is possibly the best single indicator of the overall fire hazard posed by a material.[22] It is defined as the ratio of the time-to-ignition to the peak heat release rate $\left(F P I=t_{\text {ign }} / p H R R\right)$. There is a connection between $F P I$ and the time to flashover, i.e. the change from small to large-scale fire.[22] A lower FPI value is associated with a shorter time to flashover suggesting that a shorter time is available for escape in a full-scale fire situation.

Perusal of Table 2 shows that all the additives except DABAP provided a substantial improvement in the FPI parameter. Both the expandable graphite at $10 \mathrm{wt} . \%$ and the intumescent additive EDAP at $27 \mathrm{wt} . \%$ resulted in more than a doubling in FPI. The best result was achieved with combinations of these two additives resulting in almost a threefold increase in the fire performance index.

\subsection{Thermal analysis of the flame retardant compounds}

Figure 13 shows TGA results for the flame retarded polyethylene compounds recorded in a nitrogen atmosphere. The pyrolysis of the neat polyethylene (containing $5 \mathrm{wt} . \%$ carbon black) commenced at ca. $260^{\circ} \mathrm{C}$. The material volatilized completely and virtually no residue was left by $600{ }^{\circ} \mathrm{C}$. Addition of the flame retardants resulted in the initiation of mass loss at lower temperatures. This phenomenon is caused by the lower thermal stability of the additives relative to the neat polymer. This explains the shorter ignition times of the flame retarded samples compared to the reference carbon black filled polyethylene. The compound containing $10 \mathrm{wt} . \% \mathrm{EG}$ showed enhanced overall mass loss up to a temperature of ca. $410{ }^{\circ} \mathrm{C}$. It would appear that the presence of the EG destabilized the polymer. The expandable graphite features highly oxidized graphene sheets which contain many different oxygencontaining functional groups that could facilitate oxidation of the polymer.[20] However, beyond ca. $410{ }^{\circ} \mathrm{C}$ all compounds showed a lower mass loss than the neat black pigmented polyethylene. The residue remaining at $600{ }^{\circ} \mathrm{C}$ was similar for the samples containing at least some intumescent flame 
retardant. It exceeded $15 \%$ but was less than $20 \%$. Just below $7 \%$ residue remained at $600{ }^{\circ} \mathrm{C}$ for the compound with $10 \mathrm{wt} . \% \mathrm{EG}$.
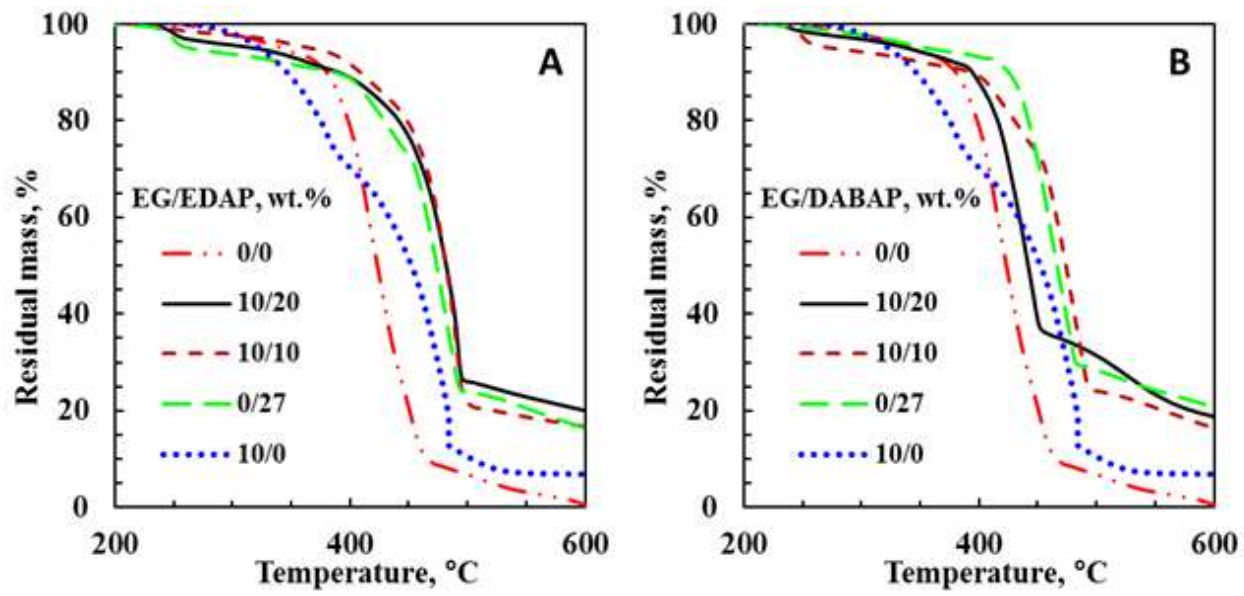

Fig. 13 TGA pyrolysis of polyethylene compounds of expandable graphite with (A) ethylenediamine phosphate (EDAP) and (B) 3,5-diaminobenzoic acid phosphate. Temperature was scanned to $600{ }^{\circ} \mathrm{C}$ at a scan rate of $10^{\circ} \mathrm{C} \min ^{-1}$ with nitrogen flowing at a rate of $50 \mathrm{~mL} \mathrm{~min}^{-1}$.

\section{CONCLUSIONS}

Expandable graphite and the phosphate salts of 3,5-diaminobenzoic acid and ethylenediamine were used to flame retard injection molding grade polyethylene with no propensity for char formation and a high heat of combustion. Ethylenediamine phosphate and 3,5-diaminobenzoic acid phosphate were tested alone in the polymer substrate and also in binary combinations with expandable graphite. Polyethylene containing $5 \mathrm{wt}$. \% carbon black was used as reference.

Cone calorimetry, laser pyrolysis and open flame fire testing coupled with infrared and optical footage were utilized to measure the fire properties of the compounds produced.

Thermal analysis highlighted the two-step expansion and four-stage oxidative decomposition of the low expansion onset temperature (ca. $210^{\circ} \mathrm{C}$ ) expandable graphite. Both phosphate compounds underwent a complex four-stage decomposition with ethylenediamine phosphate, releasing ammonia vapor and expanding explosively, while 3,5-diaminobenzoic acid phosphate released $\mathrm{CO}_{2}$ gas producing an effective charring effect.

Open flame fire testing indicated that the addition of a second flame retardant to an EG containing system caused the temperature profile around the point of flame exposure to be flattened and to spread towards the edges of the test specimen. This effect also caused a decrease in the maximum temperature reached at any specific exposure time when compared to the single flame retardant and non-flame retarded compounds. This in turn extends the time to failure and in the case of the $10 \mathrm{wt} . \% / 20 \mathrm{wt} . \%$ EG/DABAP system and both binary EDAP systems, completely prevented burn through with the compounds only failing once their melting point are exceeded. All flame retarded compounds prevented polymer flow but in some cases increased the propensity of the compounds to ignite. Interestingly, the best result was observed for the $10 \mathrm{wt} . \% / 10 \mathrm{wt} . \%$ EG/EDAP system which delivered the best ignition and burn through resistance and produced the lowest temperature profile. This indicates possible synergism between EG and EDAP at this content which outperforms both the $10 \mathrm{wt} . \%$ EG and $27 \mathrm{wt}$.\% EDAP systems which both meet a UL-94 V-0 fire rating.

The common trend between the barrier properties delivered and the temperature reached was further reinforced by the laser pyrolysis results which also indicated that the intumescent additives 
provided for better thermal shielding of the polymer substrate. They lowered the maximum temperature reached and decreased the mass loss rate. Laser pyrolysis indicated increased performance in both $10 \mathrm{wt} . \% / 10 \mathrm{wt} . \%$ binary compounds over their $10 \mathrm{wt} . \% / 20 \mathrm{wt} . \%$ counterparts, further reinforcing the results obtained from open flame fire testing. The results obtained from open flame fire testing and laser pyrolysis mirror those obtained from cone calorimeter testing indicating the utility of these methods as low cost alternatives for preliminary fire testing. The EG and EDAP additives, especially when used in combination, provided substantial improvements in the fire performance index.

\section{Acknowledgements}

This work is based upon research supported by the South African Research Chairs Initiative of the Department of Science and Technology (DST) and the National Research Foundation (NRF). Any opinion, findings and conclusions or recommendations expressed in this material are those of the authors and therefore the NRF ad DST do not accept any liability with regard thereto.

\section{References}

1. Weil, E.D. and S.V. Levchik, Flame retardants in commercial use or development for polyolefins. Journal of Fire Sciences, 2008. 26(1): p. 5-43.

2. Dasari, A., et al., Recent developments in the fire retardancy of polymeric materials. Progress in Polymer Science, 2013. 38(9): p. 1357-1387.

3. Qu, B. and R. Xie, Intumescent char structures and flame-retardant mechanism of expandable graphite-based halogen-free flame-retardant linear low density polyethylene blends. Polymer International, 2003. 52(9): p. 1415-1422.

4. Xie, R. and B. Qu, Expandable graphite systems for halogen-free flame-retarding of polyolefins. I. Flammability characterization and synergistic effect. Journal of Applied Polymer Science, 2001. 80(8): p. 1181-1189.

5. Xie, R. and B. Qu, Expandable graphite systems for halogen-free flame-retarding of polyolefins. II. Structures of intumescent char and flame-retardant mechanism. Journal of Applied Polymer Science, 2001. 80(8): p. 1190-1197.

6. Pang, X.Y. and M. Song, Preparation and anti-flame capability of expandable graphite. Advanced Materials Research, 2012. 560-561: p. 779-783.

7. Sun, Z., et al., Effect of the particle size of expandable graphite on the thermal stability, flammability, and mechanical properties of high-density polyethylene/ethylene vinylacetate/expandable graphite composites. Polymer Engineering and Science, 2013.

8. Han, Z., Y. Li, and H. Zhao. An investigation on synergistic effect of EG with IFR in polyethylene. 2007.

9. Camino, G., L. Costa, and G. Martinasso, Intumescent fire-retardant systems. Polymer Degradation and Stability, 1989. 23(4): p. 359-376.

10. Wang, J.Q. and W.K. Chow, A brief review on fire retardants for polymeric foams. Journal of Applied Polymer Science, 2005. 97(1): p. 366-376.

11. Lewin, M., Synergistic and catalytic effects in flame retardancy of polymeric materials - an overview. Journal of Fire Sciences, 1999. 17(1): p. 3-19.

12. Furdin, G., Exfoliation process and elaboration of new carbonaceous materials. Fuel, 1998. 77(6): p. 479-485.

13. Camino, G., et al., Mechanism of Expandable Graphite Fire Retardant Action in Polyurethanes, in Fire and Polymers. 2001, American Chemical Society. p. 90-109.

14. Wissler, M., Graphite and carbon powders for electrochemical applications. Journal of Power Sources, 2006. 156(2): p. 142-150. 
15. Chung, D.D.L., Exfoliation of graphite. Journal of Materials Science, 1987. 22(12): p. 4190 4198.

16. Chung, D.D.L., Review: Graphite. Journal of Materials Science, 2002. 37(8): p. 1475-1489.

17. Babrauskas, V. and R.D. Peacock, Heat release rate: The single most important variable in fire hazard. Fire Safety Journal, 1992. 18(3): p. 255-272.

18. Kruger, H.J.F., W.W.; Mhike, W.; Taute, A.; Ofosu, O., Cone calorimeter study of polyethylene flame retarded with expandable graphite and intumescent fire retardant additives. 2014.

19. Focke, W.W., et al., Polyethylene flame retarded with expandable graphite and a novel intumescent additive. Journal of Applied Polymer Science, 2014: p. n/a-n/a.

20. Focke, W.W., et al., Characterization of commercial expandable graphite fire retardants. Thermochimica Acta, 2014. 584: p. 8-16.

21. Kruger, H.J., et al., Cone calorimeter study of polyethylene flame retarded with expandable graphite and intumescent fire-retardant additives. Journal of Fire Sciences, 2014.

22. Hirschler, M.M.S., S. in Flame Retardants 92. 1992. London/New York: Elsevier Applied Science. 